\title{
Macrophage migration inhibitory factor levels in the vitreous of patients with proliferative diabetic retinopathy
} Yoshinori Mitamura, Shinobu Takeuchi, Akira Matsuda, Yoshitsugu Tagawa, Yuka Mizue,
Jun Nishihira
Department of Ophthalmology, Toho University Sakura Hospital, Sakura, Japan Y Mitamura S Takeuchi

Department of Ophthalmology, Hokkaido University School of Medicine, Sapporo, Japan A Matsuda

Y Tagawa

Central Research Institute, Hokkaido University School of Medicine, Sapporo,

Japan

J Nishihira

Sapporo

Immunodiagnostic Laboratory, Sapporo, Japan

Y Mizue

Correspondence to: Yoshinori Mitamura, MD, Department of Ophthalmology, Toho University Sakura Hospital, 564-1 Shimoshizu, Sakura, Chiba 285-8741, Japan ophtsakura@i.bekkoame.ne.jp

Accepted for publication 28 January 2000

\begin{abstract}
Aims-To assess the potential role of macrophage migration inhibitory factor (MIF) in the pathogenesis of proliferative diabetic retinopathy (PDR).

Methods-MIF levels were assayed in the vitreous and paired serum samples of 73 consecutive patients with PDR (32 eyes) and macular hole or idiopathic epiretinal membrane (controls, 41 eyes). An enzyme linked immunosorbent assay technique was used to determine the concentrations of MIF.

Results-The median vitreous level of MIF was $11.93 \mathrm{ng} / \mathrm{ml}$ (range 4.16-103.85) in the patients with PDR, and $1.79 \mathrm{ng} / \mathrm{ml}$ (undetectable-8.93) in the controls. Vitreous levels in eyes with PDR were significantly greater than those in the controls $(p<0.0001)$. Vitreous levels were significantly higher than serum levels in eyes with PDR $(p=0.0026)$. MIF levels were significantly higher in the vitreous of PDR patients with severe fibrous proliferation than in those with slight proliferation $(\mathrm{p}<0.05)$.

Conclusion-The results indicate increased levels of MIF in the vitreous of patients with PDR and a significant association between MIF levels and grades of fibrous proliferation, suggesting the possibility that MIF may play a part in the development of the proliferative phase of PDR.
\end{abstract}

(Br F Ophthalmol 2000;84:636-639)

Macrophage migration inhibitory factor (MIF) was the first $T$ cell derived soluble lymphokine reported to prevent random migration of macrophages and to recruit macrophages at inflammatory loci. ${ }^{1} \mathrm{MIF}$ also enhances macrophage activity such as adherence, motility, and phagocytosis. $^{2}$ Recent studies have revealed that MIF has an important role as a proinflammatory cytokine. ${ }^{3} \mathrm{MIF}$ is induced by lipopolysaccharides and stimulates TNF- $\alpha$ mRNA expression. ${ }^{4}$ However, the precise biological function of MIF remains undefined. With respect to the eye, we reported that in rat retina, MIF is localised in astrocytes, Müller cells, and pigment epithelial cells. ${ }^{3}$ We also reported that vitreous MIF levels increased in proliferative vitreoretinopathy (PVR) and that there was a significant association between MIF levels and PVR grades. ${ }^{5}$

Although the pathogenesis of proliferative vitreoretinal disorders such as proliferative dia- betic retinopathy (PDR) or PVR is also not completely understood, increasing interest has focused on the role of inflammatory reactions and immune phenomena. Immunohistochemical studies show the presence of several immunocompetent cells (activated $\mathrm{T}$ lymphocytes, B lymphocytes, macrophages, cells expressing human leucocyte antigen (HLA)-DR and HLA-DQ, and deposits of immunoglobulins) in preretinal membranes of PDR. ${ }^{6-10}$ Experimental and clinical studies have confirmed an important role for macrophages in the pathogenesis of proliferative vitreoretinal disorders. ${ }^{11}$ In addition, the chemokines that induce both chemotaxis and chemokinesis of particular leucocyte populations have been identified in vitreous fluid specimens from patients with PDR. ${ }^{12-14}$

Therefore, we investigated the vitreous of patients with PDR and other vitreoretinal disorders for the presence of MIF in an attempt to determine whether or not there is a correlation between vitreous MIF levels and clinical grades of PDR.

\section{Materials and methods}

PATIENTS

This study was carried out with approval from the institutional review committee. Informed consent was obtained from each patient to the collection of samples.

The study included 73 consecutive eyes of 73 patients who underwent pars plana vitrectomy in Toho University Sakura Hospital. Undiluted vitreous samples and paired serum samples were collected from 32 patients with PDR (13 females and 19 males ranging in age from 23 to 71 years (mean 50.1)) and 41 patients with macular hole (29 patients) or idiopathic epimacular membrane (12 patients) (controls; 26 females and 15 males ranging in age from 25 to 77 years (mean 63.5)).

It has been reported that MIF is secreted by $\mathrm{T}$ cells, ${ }^{1}$ macrophages, ${ }^{4}$ monocytes, ${ }^{15}$ eosinophils, ${ }^{16}$ and other blood elements, so we assumed that the blood contains highly concentrated MIF. Before this study, we investigated venous blood and serum samples of 16 patients (PDR; 12 patients, controls; four patients; these patients were included in this study) for the presence of MIF. The MIF levels of the venous blood were 1481-6843 ng/ml (mean 3159 (SD 1326)), and serum MIF levels were $3.97-12.28 \mathrm{ng} / \mathrm{ml}$ (6.54 (2.72)), suggesting that blood cells contain highly concentrated MIF. This result indicates the possibility that vitreous MIF levels may be affected 
by vitreous haemorrhage. Therefore, only the PDR cases with no or little vitreous haemorrhage $(90 \%$ or more area of the fundus was clearly visible) were included in this study. We also excluded patients who had a history of vitreoretinal surgery before sampling.

Of the 32 PDR cases, 30 had tractional retinal detachment and two had macular oedema. Six of the 32 PDR cases had no vitreous haemorrhage, and the others had slight vitreous haemorrhage. Three of the 32 PDR patients had rubeotic glaucoma.

The clinical ocular findings were graded at the time of vitrectomy with respect to the amount of fibrous proliferation and preoperative retinal photocoagulation. ${ }^{17}$ The degree of fibrous proliferation was graded as follows: no apparent fibrous proliferation $=0$, fibrous proliferation around the disc only $=1$, fibrous proliferation around the vascular arcade $=2$, and fibrous proliferation throughout the posterior pole $=3$. The extent of retinal photocoagulation before vitrectomy was graded as follows: no retinal photocoagulation $=0$, focal retinal photocoagulation $=1$, panretinal photocoagulation $(P R P)=2$, supplemental retinal photocoagulation after the initial $\mathrm{PRP}=3$.

\section{SAMPLE COLLECTION}

The vitreous samples were obtained during pars plana vitrectomy. Before intraocular infusion, the vitreous cutter was used to remove the vitreous, but ensuring that it was not mixed with blood. Special attention was paid with PDR cases: the vitreous gel of the superior vitreous cavity was aspirated to prevent the mixture of vitreous haemorrhage which usually exists in the inferior vitreous cavity. The vitreous humour was collected undiluted and stored in a syringe at $-80^{\circ} \mathrm{C}$ until the assay was performed.

The serum samples from each patient were collected before the operation.

PREPARATION OF RABBIT POLYCLONAL

ANTIBODIES AGAINST HUMAN MIF

Polyclonal anti-human MIF serum was generated by immunising New Zealand White rabbits with purified recombinant human MIF. Human recombinant MIF was expressed in $E$ coli and purified to homogeneity as previously described. ${ }^{18}$ In brief, the rabbits were inoculated intradermally with $100 \mu \mathrm{g}$ of MIF diluted in complete Freund adjuvant at weeks 1 and 2, and with $50 \mu \mathrm{g}$ of MIF diluted in incomplete Freund adjuvant at week 4 . Immune serum was collected 1 week after the last inoculation. The IgG fraction was prepared using Protein A Sepharose (Pharmacia, Uppsala, Sweden) according to the manufacturer's protocol.

MIF ANALYSIS

We employed the quantitative "sandwich" enzyme linked immunosorbent assay (ELISA) technique in this study. Briefly, the anti-human MIF antibody was added to each well of a 96 well microtitre plate and left for 1 hour at room temperature. All wells were filled with PBS containing bovine serum albumin $(1 \%)$ for blocking and left for 1 hour at room tempera- ture. After removal of blocking solution and washing, $10 \mu \mathrm{l}$ of samples were added in duplicate to individual wells and incubated for 1 hour at room temperature. After washing, $50 \mu \mathrm{l}$ of biotin conjugated anti-human MIF antibody was added to each well. Following incubation for 1 hour at room temperature, avidin conjugated horseradish peroxidase (Pierce, Rockford, IL, USA) was added to individual wells and incubated for 1 hour at room temperature. A volume of $50 \mu$ of substrate solution containing o-phenylenediamine (Wako, Osaka, Japan) and hydrogen peroxide in citrate phosphate buffer $(\mathrm{pH}$ 5.0) were added. After incubation for 20 minutes at room temperature, the reaction was terminated with $1 \mathrm{~N}$ sulphuric acid. The absorbance at $492 \mathrm{~nm}$ was measured using an ELISA plate reader (Bio-Rad, Model 3550). Duplicate readings were averaged.

This ELISA method consistently detected MIF concentrations of higher than $1 \mathrm{ng} / \mathrm{ml}$. For statistical calculations, samples with undetectable levels were entered as $1 \mathrm{ng} / \mathrm{ml}$.

\section{PROTEIN AND HAEMOGLOBIN CONCENTRATIONS} OF THE VITREOUS

Protein in all the vitreous samples was determined using a Pierce protein assay kit (Pierce, Rockford, IL, USA).

In all cases, vitreous haemoglobin levels were investigated to confirm that no blood was mixed into the vitreous samples. Vitreous haemoglobin levels were determined using spectrophotometry (Sysmex, NE-8000). The detection limit was defined as $0.1 \mathrm{~g} / \mathrm{dl}$. (Three PDR patients in which vitreous haemoglobin was detected have been excluded from this study.)

\section{STATISTICAL ANALYSIS}

In view of the skewed distribution, all values are displayed as the median value and range, unless otherwise indicated. Data were statistically analysed with the Mann-Whitney U tests for comparison of the two groups and with the Kruskal-Wallis test for multiple groups in the vitreous concentrations of MIF and protein. Comparisons between serum and vitreous levels of MIF were examined by Wilcoxon signed ranks test. Levels of statistical significance were set at $\mathrm{p}<0.05$.

\section{Results}

There was no significant difference in intravitreous protein levels between the patients with PDR (median $5.65 \mathrm{mg} / \mathrm{ml}$, range 1.28-27.30 $\mathrm{mg} / \mathrm{ml}$ ) and the controls $(4.70 \mathrm{mg} / \mathrm{ml}, 1.04-$ $7.54 \mathrm{mg} / \mathrm{ml})(\mathrm{p}=0.0869$, Mann-Whitney U test).

The vitreous MIF levels were undetectable in only 10 of 41 control samples. The MIF concentrations of all subject eyes (73 eyes) ranged from undetectable to $103.85 \mathrm{ng} / \mathrm{ml}$.

The median vitreous levels of MIF were $11.93 \mathrm{ng} / \mathrm{ml}$ (range 4.16-103.85) in eyes with PDR and $1.79 \mathrm{ng} / \mathrm{ml}$ (undetectable-8.93 $\mathrm{ng} / \mathrm{ml}$ ) in the controls (Fig 1). The vitreous MIF levels in the PDR eyes were significantly greater than those in the controls $(\mathrm{p}<0.0001$, 


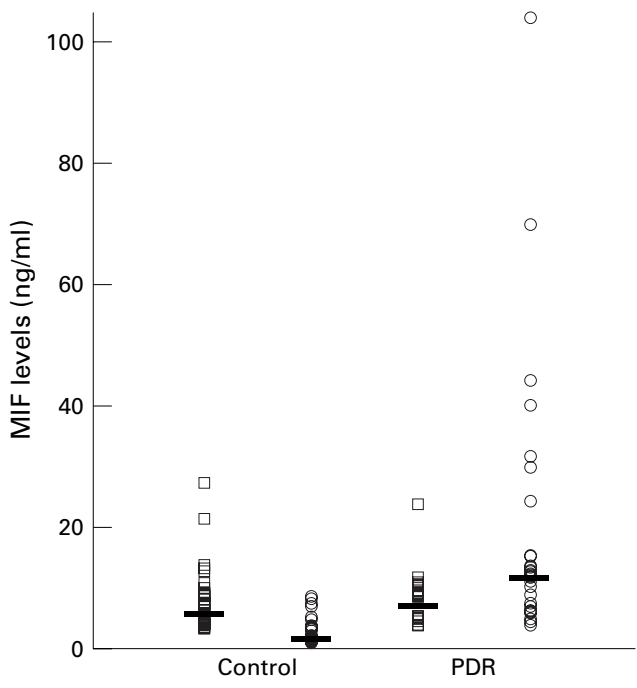

Figure 1 Macrophage migration inhibitory factor (MIF) levels in the vitreous and paired serum samples from eyes with macular hole or idiopathic epiretinal membrane (controls: $n=41$ ) and proliferative diabetic retinopathy (PDR: $n=32)$. Open circles represent vitreous levels and open squares represent serum levels. The horizontal lines indicate the median concentration in each group. The vitreous MIF levels in PDR were significantly greater than levels in the controls $(p<0.0001)$. Vitreous MIF levels were significantly higher than serum MIF levels in PDR $(p=0.0026)$, but significantly lower than serum levels in the controls $(p<0.0001)$

Mann-Whitney U test). The MIF concentrations in the serum were $7.17 \mathrm{ng} / \mathrm{ml}$ (3.9823.95) in eyes with PDR and $5.76 \mathrm{ng} / \mathrm{ml}$ (3.42-27.43) in the controls. Vitreous MIF levels were significantly higher than serum MIF levels in PDR ( $p=0.0026)$, but significantly lower than serum levels in the controls $(\mathrm{p}<0.0001)$ (Wilcoxon signed ranks test).

In eyes with PDR, fibrous proliferation ranged from grade 1 to grade 3 . The MIF level was $6.96 \mathrm{ng} / \mathrm{ml}(4.16-11.66)$ in the eyes with grade 1 (four eyes), $11.19 \mathrm{ng} / \mathrm{ml}$ (4.65-31.71) in grade 2 (19 eyes), and $30.24 \mathrm{ng} / \mathrm{ml}$ (5.77-103.85) in grade 3 (nine eyes) (Fig 2, Table 1). Significant differences were found among these three groups $(p=0.0199$, Kruskal-Wallis test). When the MIF levels of the three groups were compared independently with each of the other groups, the levels were significantly greater in grade 3 than in grades 1 or $2(p=0.0076, p=0.0009$, respectively, Fisher's PLSD).

In the PDR cases, the degree of preoperative retinal photocoagulation ranged from grades 0 to 3. The MIF level was $12.82 \mathrm{ng} / \mathrm{ml}$ (5.07-31.71) in grade 0 (four eyes), 42.18 $\mathrm{ng} / \mathrm{ml}$ (6.83-103.85) in grade 1 (four eyes), $11.66 \mathrm{ng} / \mathrm{ml}$ (4.65-44.52) in grade 2 (21 eyes), and $5.77 \mathrm{ng} / \mathrm{ml}(4.16-6.76)$ in grade 3 (three

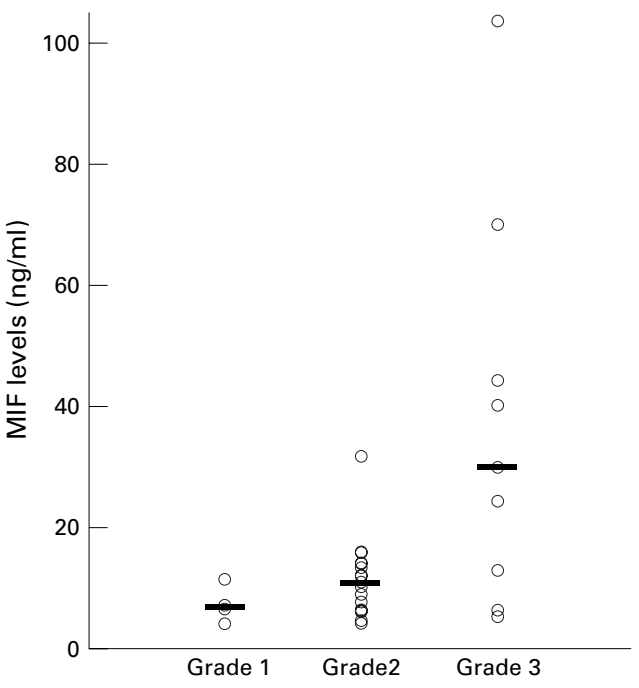

Figure 2 Macrophage migration inhibitory factor (MIF) levels in the vitreous samples from eyes with grade $1(n=4)$, grade $2(n=19)$, and grade $3(n=9)$ of fibrous proliferation in proliferative diabetic retinopathy (PDR). The horizontal lines indicate the median concentration in each group.

Vitreous MIF levels were significantly greater in grade 3 than in grades 1 or 2 ( $p=0.0076, p=0.0009$, respectively).

eyes) (Table 1). No significant differences were found among these four groups $(p=0.0585$, Kruskal-Wallis test), but there was a tendency towards lower levels in eyes with grade 3 .

As for vitreous haemorrhage, the MIF concentration was $12.99 \mathrm{ng} / \mathrm{ml}$ (6.76-40.55) in eyes without vitreous haemorrhage (six eyes) and $11.93 \mathrm{ng} / \mathrm{ml}(4.16-103.85)$ in eyes with slight vitreous haemorrhage (26 eyes) (Table $2)$. No significant difference was found between these two groups ( $\mathrm{p}=0.4991$, MannWhitney U test).

In the three eyes with rubeotic glaucoma, the MIF level was $30.24 \mathrm{ng} / \mathrm{ml}$ (24.71-103.85). In the other 29 eyes without glaucoma, the level was $11.19 \mathrm{ng} / \mathrm{ml}$ (4.16-70.15) (Table 2). MIF levels were significantly greater in eyes with rubeotic glaucoma than in eyes without it ( $p=0.0217$, Mann-Whitney U test).

Vitreous haemoglobin concentrations were undetectable in all subjects.

\section{Discussion}

MIF was the lymphokine reported to prevent random migration of macrophages and to recruit macrophages at inflammatory loci. ${ }^{1}$ MIF also enhances macrophage adherence, motility, and phagocytosis. ${ }^{2}$ These MIF actions are similar to the actions of chemokines, such as monocyte chemotactic protein-1 (MCP-1) or macrophage colony stimulating factor. It was reported that the vitreous levels of MCP-1

Table 1 Vitreous MIF levels* and clinical findings (1)

\begin{tabular}{lllll}
\hline & Grade 0 & Grade 1 & Grade 2 & Grade 3 \\
\hline Fibrous proliferation & - & $\begin{array}{l}6.96(4.16-11.66) \dagger \\
(\mathrm{n}=4)\end{array}$ & $\begin{array}{l}11.19(4.65-31.71) \dagger \\
(\mathrm{n}=19)\end{array}$ & $\begin{array}{l}30.24(5.77-103.85) \dagger \\
(\mathrm{n}=9)\end{array}$ \\
Preoperative photocoagulation & $\begin{array}{l}(\mathrm{n}=0) \\
12.82(5.07-31.71) \ddagger \\
(\mathrm{n}=4)\end{array}$ & $\begin{array}{l}42.18(6.83-103.85) \ddagger \\
(\mathrm{n}=4)\end{array}$ & $\begin{array}{l}11.66(4.65-44.52) \ddagger \\
(\mathrm{n}=21)\end{array}$ & $\begin{array}{l}5.77(4.16-6.76) \dagger \\
(\mathrm{n}=3)\end{array}$ \\
\hline
\end{tabular}

*All values indicate vitreous MIF levels given as the median (range) $\mathrm{ng} / \mathrm{ml}$. $t \mathrm{p}<0.05$. Significant differences were found among 3 groups $(\mathrm{p}=0.0199)$.

$\ddagger N S=$ no significant differences were found among 4 groups $(\mathrm{p}=0.0585)$, although there was a tendency toward lower levels in eyes with grade 3 . 
Table 2 Vitreous MIF levels * and clinical findings (2)

\begin{tabular}{lll}
\hline & + & - \\
\hline Vitreous haemorrhage & $11.93(4.16-103.85) \dagger$ & $12.99(6.76-40.55) \dagger$ \\
& $(\mathrm{n}=26)$ & $\begin{array}{l}(\mathrm{n}=6) \\
\text { Rubeotic glaucoma }\end{array}$ \\
& $30.24(24.71-103.85) \ddagger$ & $(\mathrm{n}=29)$ \\
\hline
\end{tabular}

*All values indicate vitreous MIF levels given as the median (range) $\mathrm{ng} / \mathrm{ml}$.

$+\mathrm{NS}=$ no significant difference was found $(\mathrm{p}=0.4991)$.

$\neq \mathrm{p}<0.05$. MIF levels were significantly greater in eyes with rubeotic glaucoma than in eyes without it $(\mathrm{p}=0.0217)$.

are elevated in eyes with PDR, and that MCP-1 may be involved in the recruitment of macrophages and monocytes into the vitreous, and in the pathogenesis of PDR. ${ }^{12-14}$ Our study indicates that MIF levels in the vitreous of patients with PDR were significantly greater than those in the controls and that there was a significant association between MIF levels and grades of fibrous proliferation. Moreover, there was a tendency towards lower levels in eyes with supplemental retinal photocoagulation after the initial PRP, and MIF levels were significantly greater in eyes with rubeotic glaucoma than in those without it. These results may suggest the possibility that MIF may be involved in the pathogenesis of PDR. MIF, as well as MCP-1, may also play a part in the recruitment of macrophages into the vitreous and in the activation of macrophages in PDR eyes.

Breakdown of the blood-ocular barrier (such as occurs with the significantly increased permeability of new retinal vessels) is an important component of the pathophysiology of PDR. Although breakdown of the bloodocular barrier might contribute to the elevation of vitreous MIF levels measured in our PDR patients, the fact that the vitreous MIF levels were significantly higher than the serum levels in the patients with PDR, but lower than serum levels in the controls, may suggest intraocular production of MIF.

Although when the vitreous samples were obtained we ensured that no blood was mixed in them, and vitreous haemoglobin concentrations were undetectable in all eyes with PDR in this study, the possibility that a minimal amount of vitreous haemorrhage might affect the vitreous MIF levels could not be completely excluded. However, if so, the effect of vitreous haemorrhage is considered smaller than the effect of the other factors, because MIF levels were not significantly different between PDR patients with a slight vitreous haemorrhage and those with no vitreous haemorrhage.

In this study, all PDR cases had no or little vitreous haemorrhage. Although PDR cases with moderate or severe vitreous haemorrhage were excluded, these PDR cases are more common than those with no or little haemorrhage. Further studies investigating the role of
MIF in PDR eyes with moderate or more vitreous haemorrhage are needed.

In conclusion, the results indicate increased levels of MIF in the vitreous of patients with PDR and a significant association between MIF levels and grades of fibrous proliferation, suggesting the possibility that MIF may play a part in the development of the proliferative phase of PDR. However, we cannot distinguish whether the increased MIF levels are the cause or the effect of PDR in this study, thus further investigations of the mechanism of MIF action are needed to understand the precise role of MIF in PDR.

This study was supported in part by the Japan National Society for the Prevention of Blindness, Tokyo.

1 Bloom BR, Bennett B. Mechanism of a reaction in vitro associated with delayed-type hypersensitivity. Science 1966;153:80-2.

2 Nathan CF, Remold HG, David JR. Characterization of a lymphocyte factor which alters macrophage function. $\mathcal{f}$ Exp (137:275-90.

3 Matsuda A, Tagawa Y, Matsuda H, et al. Expression of macrophage migration inhibitory factor in rat retina and its immunohistochemical localization. F Neuroimmunol 1997; 77:85-90

4 Calandra T, Bernhagen J, Mitchell RA, et al. The macrophage is an important and previously unrecognized source of macrophage migration inhibitory factor. $\mathcal{F}$ Exp Med 1994;179:1895-902.

5 Mitamura Y, Takeuchi S, Matsuda A, et al. Macrophage migration inhibitory factor levels in the vitreous of patients with proliferative vitreoretinopathy. Am f Ophthalmol 1999; 128:963-5.

6 Tang S, Scheiffarth OF, Thurau SR, et al. Cells of the immune system and their cytokines in epiretinal membranes and in the vitreous of patients with proliferative diabetic retinopathy. Ophthalmic Res 1993;25:177-85.

7 Tang S, Le-Ruppert KC. Activated T lymphocytes in epiretinal membranes from eyes of patients with proliferaepiretinal membranes from eyes of patients with prolifera1995;233:21-5.

8 Esser P, Heimann K, Wiedemann P. Macrophages in proliferative vitreoretinopathy and proliferative diabetic retinopathy: differentiation of subpopulations. $\mathrm{Br} \mathcal{F} O \mathrm{Ph}$ thalmol 1993;77:731-3.

9 Baudouin C, Fredj-Reygrobellet D, Gordon WC, et al. Immunohistologic study of epiretinal membranes in prolferative vitreoretinopathy. Am f Ophthalmol 1990; 110:5938.

10 Limb GA, Alam A, Earley O, et al. Distribution of cytokine proteins within epiretinal membranes in proliferative vitreoretinopathy. Curr Eye Res 1994;13:791-8.

11 Hui YN, Goodnight R, Sorgente N, et al. Fibrovascular proliferation and retinal detachment after intravitreal injection of activated macrophages in the rabbit eye. Am $f$ Ophthalmol 1989;108:1762-84.

12 Elner SG, Elner VM, Jaffe GJ, et al. Cytokines in proliferative diabetic retinopathy and proliferative vitreoretinopathy. Curr Eye Res 1995;14:1045-53.

13 Abu El-Asrar AM, Van Damme J, Put V, et al. Monocyte chemotactic protein-1 in proliferative vitreoretinal disorders. Am f Ophthalmol 1997;123:599-606.

14 Capeans C, Victoria de rojas M, Lojo S, et al. C-C chemokines in the vitreous of patients with prolferative vitreoretinopathy and preliferative diabetic retinopathy. Retina 1998;18:546-50

15 Bacher M, Metz CN, Calandra T, et al. An essential regulatory role for macrophage migration inhibitory factor in T-cell activation. Proc Natl Sci USA 1996;93:7849-54.

16 Rossi AG, Haslett C, Hirani N, et al. Human circulating eosinophils secrete macrophage migration inhibitory factor (MIF). Potential role in asthma. F Clin Invest 1998;101: 2869-74.

17 Hirase K, Ikeda T, Sotozono C, et al. Transforming growth factor $\beta_{2}$ in the vitreous in proliferative diabetic retinopathy. factor $\beta_{2}$ in the vitreous in proliferat

18 Nishihira J, Kuriyama T, Nishino H, et al. Purification and characterization of human macrophage migration inhibitory factor: evidence for specific binding to glutathione and formation of subunit structure. Biochem Mol Biol Int 1993; 31:841-50. 